\title{
Crítica a la autoridad burocrática en Tras la virtud: MacIntyre contra Weber y con Weber
}

Critique of the Ideology of Bureaucratic Authority in
AfterVirtue: MacIntyre Against Weber and with Weber

\author{
Ignacio Serrano del Pozo \\ Universidad Santo Tomás, Chile \\ iserrano@santotomas.cl
}

Recibido: 27/04/2016 • Aceptado: 02/02/2017

\begin{abstract}
Resumen
Tras la virtud contiene una poderosa crítica a la autoridad burocrática o gerencial de base weberiana. En ella Alasdair MacIntyre ataca el carácter ficticio de los dos atributos que poseería esta forma de dominación: la eficacia organizativa y la predictibilidad de sus resultados. El objetivo de este trabajo es mostrar que la «autoridad burocrática» es la principal ideología de dominación del tiempo presente detectada por MacIntyre. Sin embargo, lejos de implicar esta postura un distanciamiento de las tesis weberianas, nuestra intención es demostrar que buena parte de los análisis que realiza el sociólogo alemán le servirán a MacIntyre para perfilar - por oposición-su idea de virtud moral, centrada en la excelencia de las prácticas y en el carácter narrativo de la vida.
\end{abstract}

Palabras clave: burocracia, ideología, A. Maclntyre, virtud moral, M. Weber.

\section{Abstract}

After Virtue contains a powerful critique of Weberian bureaucratic authority, or managerial authority. A. MacIntyre attacks the fictional feature of the two main attributes that this form of domination possesses according to Max Weber: organizational effectiveness and total predictability of action. The purpose of this paper is to analyze «bureaucratic authority» as the main ideology of domination for the present time that MacIntyre detects. Nevertheless, in the same line of research, we will attempt to show that this critique does not entail a departure from Weber, but rather help MacIntyre, by opposition, to reconstruct the idea of moral virtue present in his ethical project.

$$
\begin{aligned}
& \text { Keywords: bureaucratic domination, } \\
& \text { Critique of Ideology, A. MacIntyre, } \\
& \text { moral virtue, M. Weber. }
\end{aligned}
$$


Introducción

Los interesados en el pensamiento de Alasdair MacIntyre han visto aparecer en los últimos años nuevas vetas de estudio que hasta entonces habían permanecidos ocultas bajo el peso de su polémico tomismo. Nos referimos fundamentalmente a los trabajos dedicados a la influencia de Marx y Aristóteles como hitos configuradores del pensamiento del autor de Tras la virtud (Knight, 2011; Blackledge, 2005). Las razones de este redescubrimiento son variadas, pero fundamentalmente obedecen a un intento por superar el pesimismo nostálgico del MacIntyre de las últimas décadas, para aventurarse en lo que se ha venido a llamar el aspecto "revolucionario, más que reaccionario" de su proyecto filosófico.

Sin embargo, salvo algunas excepciones (Breen, 2012; Knight, 2007; MacMylor, 1994), llama la atención la escasa importancia que se le ha dado en este revisionismo a la influencia que habría ejercido Max Weber en la obra de MacIntyre. Más llamativo aún si se considera que es el sociólogo alemán quien proporciona buena parte del aparato conceptual con la que el pensador escocés entiende la Modernidad. El propósito de este trabajo es estudiar esta influencia en vista de demostrar dos tesis principales. La primera de ellas es que Max Weber es la figura más determinante en la compresión crítica que tiene Alasdair MacIntyre de la sociedad contemporánea, tanto de sus aspiraciones como de sus patologías. Es más, creemos que si se repara en conceptos claves con los que MacIntyre cuestiona las trasformaciones sociales y morales a las que hemos sido conducidos por el sistema capitalista y por el liberalismo político moderno, nos referimos a las nociones de autoridad gerencial o individualismo burocrático, el peso específico de Weber es mayor que el que puede ejercer Marx o Nietzsche, figuras reconocidamente importantes en el discurso macinteryano. La segunda tesis -y probablemente la más arriesgada-refiere a la posibilidad de que la influencia de MaxWeber 
no sólo se limite a la parte crítica o pars destruens, sino que también incluya la formulación constructiva del proyecto macinteryano de rehabilitación de la virtud aristotélica. En esta línea de trabajo, nos atrevemos a formular que hay buenas razones para suponer que conceptos capitales contenidos en Tras la virtud, como son los de excelencia de las prácticas e impredictibilidad de los asuntos humanos, solo pueden ser entendidos plenamente si se los considera como la respuesta alternativa u opuesta al ideal técnico de efectividad y al ideal sociológico de control, ambos típicamente weberianos.

Señalado lo anterior, conviene aclarar que la tesis propuesta no es evidente, puesto que son varias las razones que permiten cuestionarla. Una de ellas se relaciona con una lectura de MacIntyre que pareciera demostrar lo contrario a lo aseverado: Max Weber, como Kant o Hume, está en las antípodas del proyecto de rehabilitación de la ética y política aristotélica; y, en cuanto figura arquetípica de la Modernidad, sus ideas condensan el fracaso del proyecto ilustrado que debe ser superado. Así, en Tras la virtud, Max Weber es el representante eximio del «emotivismo», corriente ética fuertemente criticada por MacIntyre, y que consiste en fundar las normas morales según valoraciones afectivas y subjetivas (MacIntyre, 2007: 30 y ss.). En escritos anteriores del filósofo escocés el asunto tampoco es muy diferente, pues Weber representa tanto al padre de la ideología de la autoridad burocrática (MacIntyre, 1977) como uno de los responsables de la sobrevaloración del poder predictivo e ideológico de las ciencias sociales (MacIntyre, 1979). En esta misma línea de trabajo, de oposición entre ambos autores, no han faltado los estudiosos que han salido a defender a Max Weber contra Alasdair MacIntyre, como es el caso de Tester (1999) o Paul de Gay (2000), quienes le reprochan al británico una lectura poco rigurosa e interesada, que intenta encasillar al sociólogo alemán en categorías éticas ajenas a su espíritu. ${ }^{1}$

1 "The question which arises is one of whether Maclntyre's allegation that Weber is an emotivist can be justified by reference to Weber's own texts rather than simply by reference to a couple of the relatively less sophisticated commentaries upon Weber. Is Maclntyre right? [....] Maclntyre is guilty of misreading Weber probably because he approaches Weber as if he were an ethics rather than as the sociologist he actually was" (Tester, 
Nuestra tesis es atípica, además, en segundo lugar, porque la literatura secundaria ha mostrado más bien que MacIntyre recoge de Max Weber aspectos ligados a la racionalidad económica y a la figura del gerente, pero no cuestiones sustantivas referidas al proyecto moderno y a la restitución de la idea de virtud y tradición. De hecho, eso explicaría que Weber aparezca entre los estudiosos de MacIntyre fundamentalmente cuando se trata sobre mercado, organización, ética de negocios o el management como práctica (Keat, 2008; Beadle, 2006; Balstad Brewer, 1997; McCann-Brownsberger, 1990; Beabout, 2013), pero no más allá. ${ }^{2}$

Para alcanzar los objetivos propuestos, se comenzará con una breve descripción de las ideas de Max Weber referidas a la burocracia, más atendiendo a su superioridad técnica como forma de administración que como mecanismo de dominio y control ${ }^{3}$. Poste-

1999: 566, 572). “En lugar de ofrecer una descripción positiva del ethos de la función pública -como Weber se esmera por hacer-, Maclntyre intenta que el Gerente burocrático se le haga responsable frente a un ideal específico de persona. El ideal en cuestión -el del ser humano completo o plenamente desarrollado- tiene su propia genealogía, derivando la mayoría de sus características de la teología cristiana" (du Gay, 2000: 102).

2 Resulta interesante constatar que en la actualidad Maclntyre es el segundo autor más citado en el ámbito de ética de la virtud, Business y Management, solo superado por Aristóteles. El estudio que respalda esta información se refiere a los trabajos registrados en Thomson-Reuters Journal of Citation Report durante los últimos 30 años (Ferrero \& Sison, 2014).

3 No es fácil resumir el planteamiento de Weber, tanto por la riqueza de sus análisis, como porque su pensamiento juega con ambivalencias que se resisten a cualquier simplificación. Esto es lo que sucede precisamente cuando aborda el proceso de racionalización de las estructuras de poder y de burocratización de la administración. Este complejo fenómeno se presenta con dos caras: por una parte como la más avanzada técnica de organización, por otra como una maquinaria de poder que congela la iniciativa individual. Así lo sintetiza Wolfgang Mommsen, uno de los principales estudiosos de la obra weberiana: "Weber's own attitude towards capitalism and rationalization was, not surprisingly, rather ambivalent. Weber was confronted here with an insoluble antinomy. First, the modern techniques of bureaucratic organization were infinitely superior to all traditional forms of social organization, namely the types of patrimonial or honorific (Honoratiorem) administration. He considered it fact of life that advanced industrial societies could no longer do without bureaucratic techniques. [...] On the other hand, Weber was all too aware of the fact that bureaucratization and rationalization were about to undermine the liberal society of his own age. They were working towards the destruction of the very social premises on which individualist conduct was dependent. They heralded a new, bureaucratized and collectivist society in which the individual was reduced to utter powerlessness" (Mommsen, 2007: 110-111). 
riormente, se abordará la crítica de MacIntyre a las ideas y postura de Weber; crítica que está presente desde sus trabajos germinales de los años '70 hasta su obra madura Tras la virtud (1984, 2007). Finalmente, se intentará demostrar cómo, no obstante esta pugna, el análisis weberiano irrumpe en la obra magna del pensador escocés para modelar los conceptos claves con los que éste caracteriza la virtud moral.

\section{La dominación burocrática en MaxWeber}

Aunque la idea de burocracia no se inicia con Max Weber, sino que tiene una historia que se remonta a las críticas que en Francia se dirigieron a fines del siglo XVIII contra el aparato administrativo de oficinistas, secretarios e inspectores; ${ }^{4}$ lo cierto es que solo con el sabio alemán la sociología, la política y la filosofía podrán descubrir en ella el signo de toda una época. Sin embargo, un primer problema que aparece a los estudiosos de la burocracia weberiana es que este autor nunca nos proporciona una definición de esta noción, a pesar de las varias páginas que le dedica (Albrow, 1970: 40). El segundo inconveniente radica en que Weber parece haber desarrollado dos cuerpos de trabajo en los que reflexiona sobre la burocracia: en uno lo hace como sociólogo, en otra como político. Como sociólogo utiliza la categoría de "tipo ideal" para analizar la burocracia como modelo de organización racional moderna, como político hace referencia al desafío implícito en la burocratización y tecnificación del régimen alemán post Bismarck (Colina \& Del Pino, 2000). Para evitar zozobrar en el mar weberiano, nos centraremos fundamentalmente en los lugares clásicos en los que se aborda esta cuestión: nos referimos

4 Para la historia de este concepto puede verse el trabajo de Martin Albrow (1970). De acuerdo con este autor, el trabajo de Weber se comprende si se atiende al contexto en el que se desarrolla su reflexión en torno a la burocracia. En esa línea, es fundamental entender cuatros grandes influencias en la reflexión weberiana: la teoría y práctica de administración germana enfocada en un sistema jerarquizado (no colectivo) de oficiales, los enfoques sociológicos de Robert Michels y de Karl Marx; y, por último, los análisis económicos e históricos de su contemporáneo Gustav von Schmoller (1970: 50). 
a Economía y Sociedad, ${ }^{5}$ un compendio de los conceptos sociológicos fundamentales y Escritos Políticos, ${ }^{6}$ colección de ensayos en los que Weber analiza el poder (casi incontrarrestable) de la burocracia al interior del Deutsches Reich.

En términos generales, habría que decir que la burocracia weberiana representa una sofisticada estructura de poder y la forma de organización típicamente moderna. En Economía y Sociedad la analiza desde la idea de dominación que, ${ }^{7}$ para efectos de este análisis, puede comprenderse como el modo de ejercer la autoridad y traspasar el poder dentro de una institución, corporación o Estado. Para este autor existen tres «tipos ideales» de dominación como formas legítimas de gobierno: la racional, la tradicional y la carismática (Weber, 2012: 172: 706 y ss.). La dominación carismática descansa en

5 Esta obra, cuyo título original es Wirtschaft und Gesellschaft, en realidad no es un libro propiamente tal, sino una serie de escritos incompletos que Weber no alcanzó a editar ni publicar pues en 1920 le sorprendió la muerte. Aunque se le considera la obra magna de este autor (más de 1200 páginas dedicadas a explicar conceptos claves de la sociología, de la economía, del derecho y de la política, campos donde Weber destacó como ninguno otro), presenta lagunas y muchas repeticiones que dificultan su lectura y comprensión. Nosotros hemos utilizado la famosa traducción de Fondo de Cultura Económica, aparecida su primera edición en 1944, y reimpresa el 2012. También en lengua española circula un libro de Weber titulado ¿Qué es la burocracia?, editado por Coyoacán, en realidad una reproducción (y nueva traducción) del capítulo IX, sección III de Economía y Sociedad referida a la "Esencia, supuestos y desarrollo de la dominación burocrática". Este célebre capítulo IX ha sido recientemente publicado en alemán (2013) como parte de la edición crítica de las obras completas de Weber: Max WeberGesamtausgabe Band I/22,4: Wirtschaft und Gesellschaft. Herrschaft.

6 Este libro recoge tres artículos que Weber publicara entre 1917 y 1919. El trabajo más importante para nuestro planteamiento es "Parlamento y gobierno en una Alemania reorganizada", colección de ensayos que aparecieron en el periódico Frankfurter Zeitung y en los que Weber reivindica un sistema parlamentario para Alemania que haga frente a un Estado autoritario (post Bismarck) y a la burocratización de los partidos. Alianza Editorial ha editado estos textos, con traducción y comentario de Joaquín Abellán. Este texto se basa en la Max Weber-Gesamtausgabe: Band I/15: Zur Politik Im Weltkrieg. Schriften und Reden 1914-1918.

7 La palabra alemana que utiliza Weber es Herrschaft, "que -como señala Bendix- destaca por igual el ejercicio del poder por parte del gobernante y la aceptación de ese ejercicio como legítimo por parte de sus adictos" (Bendix, 2012: 433). Para la realización de este estudio se ha utilizado la palabra "dominación», pues esta se ha transformado en la traducción común. El mismo Max Weber indica: "Debe entenderse por dominación la probabilidad de encontrar obediencia a un mandato determinado" (Weber, 2012: 43, 170). 
la autoridad «fuera de lo común» o «extra cotidiana» ejercida por una persona ejemplar, héroe o santo. Por su parte, la tradicional se sostiene en un conjunto de ordenaciones avaladas por la costumbre y la sacralidad de los «tiempos inmemoriales». Y la dominación racional, se basa en «ordenaciones impersonales y objetivas» que han sido estatuidas por personas competentes o designadas para ello. Dado justamente que esta dominación es sostenida por un cuadro de funcionarios encargados de la administración, Weber señala que ella se identifica - generalmente-con la «burocracia» (Weber, 2012: 175). Esta burocracia puede estar operando en los aparatos de gobierno, lo mismo que en las empresas, en hospitales públicos como en clínicas privadas, en el ejército como en una orden religiosa, pues en todos estos espacios encontramos la presencia de funcionarios especializados, contratados para una labor específica bajo un régimen asalariado (sin posesión de los bienes a administrar) (Weber, 2012: 176: 708$).^{8}$

En los Escritos políticos la burocracia también es una forma de dominación, caracterizada por la primacía del «funcionariado» o de la actuación administrativa cotidiana (Weber, 1991: 96-97). Pero su contraparte fundamental no es una realidad ideal, sino más bien el dirigente político y el Parlamento ("un parlamento que trabaje, no un parlamento conversador”), únicas instancias capaces de limitar y guiar el exceso de poder de los funcionarios (Weber, 1991: 142).

Sin embargo, no es la mera existencia de funcionarios los que caracteriza a las burocracias como sistema moderno de dominación. Weber señala -haciendo gala de una cultura enciclopédica-que también encontramos administración burocrática en el funcionario egipcio, el funcionario del imperio romano, como también en Bizancio y en China. Lo que realmente caracteriza a las burocracias modernas es la "especialización de índole racional y técnica" de su cuerpo administrativo (Weber, 1991: 113). Esto es lo que proporciona a esta forma de dominio una relativa superioridad sobre otros regímenes

8 La misma expresión die Bürokratie "puede tener, por ejemplo, el significado de una forma de «racional de administración» [...] pero, a veces, puede también significar cuerpo de funcionarios, considerados como grupo. En este último sentido la citada expresión es, pues, equivalente de das Beamtentum" (Beetham, 1979: 99). 
de administración. "Se tiene que elegir entre la burocratización y el diletantismo de la administración; y el gran instrumento de la superioridad de la administración burocrática es éste: el saber profesional especializado (Weber, 2012: 178). En la administración burocrática el funcionario domina no en razón de su prestigio o recursos, pues de ellos carece, sino gracias a este saber. Nuestro autor habla de un “saber de servicio" (Weber, 2012: 179). La misma noción de "secreto profesional” está relacionada con esto que venimos diciendo: en las burocracias aparece un saber de experto o especialista que está vedado para los otros. Este saber es, además, objetivo, en el sentido que procede sin odio ni preferencia (sine ira et studio es la expresión usada). Formulado en términos kantianos - como hace el mismo Weber- esto significaría que la burocracia es ajena a cualquier patología distinta del mero deber estricto (Weber, 2012: 179). Este actuar del funcionario "sin acepción de personas", tratando a todos por igual, evita fricciones y conflictos dentro de la organización (Weber 2012: 732). Pero además, esta impersonalidad de la burocracia, su atención a reglamentos analizados de manera objetiva, hace de ella -como lo indica Weber en reiteradas ocasiones- la forma más racional de ejercer poder. ${ }^{9}$

Con todo, el motivo fundamental que explicaría la superioridad de la administración burocrática por sobre otras formas de organización está dada por la mecanización o tecnificación de sus procedimientos. "La razón decisiva que explica el progreso de la organización burocrática ha sido siempre su superioridad técnica sobre cualquier otra organización” (Weber, 2012: 730). Entendiendo aquí técnica o mecánica como la capacidad para proceder según reglas procedimentales precisas y rigurosas, ajenas a los factores humanos de quienes las ejecutan. En ese sentido, el mismo Weber admite que la

9 "La administración burocrático-monocrática, atenida al expediente, es a tenor de toda la experiencia la forma racional de ejercerse una dominación" (Weber, 2012: 178). "La dominación burocrática es específicamente racional en el sentido de su vinculación a reglas discursivamente analizables" (Weber, 2012: 195). "La acción racionalmente socializada de una estructura de dominación encuentra en la «burocracia» su tipo específico" (Weber, 2012: 706). "La burocracia tiene un carácter «racional»: la norma, la finalidad, el medio, la impersonalidad «objetiva» dominan su conducta" (Weber, 2012: 752). 
virtud de la burocracia está dada precisamente por su "deshumanización” (Weber, 2012: 732). En los Escritos Políticos refiere a la organización burocrática como una maquina viviente o espíritu coagulado superior a cualquier poder, pero por ello precisamente más temible, capaz de producir "el armazón de la servidumbre del futuro" (Weber, 1991: 115).

En atención a las limitaciones de este trabajo y dado que nos interesa la lectura que MacIntyre hace deWeber, dejamos aquí este interesantísimo diagnóstico ${ }^{10}$ para decir algo sobre los dos rasgos claves que posibilitan la mecanización del proceso burocrático: la eficiencia y la calculabilidad. Si bien existen autores que -no sin razón- reclaman que Weber no pone explícitamente a la eficiencia como característica de la burocracia (Albrow, 1970: 64), esta idea pareciera resumir muy bien una de sus características más relevante. Para Weber la burocracia es eficaz en la medida que usa de los medios de comunicación disponibles, pero fundamentalmente porque se sostiene en el principio de división de trabajo típicamente modernos (Weber, 2012: 730731). Su eficiencia se basa en la utilización de funcionarios especializados que se dedican exclusivamente a una tarea y van adiestrándose en esa limitada área de competencia. Esto diferencia a la burocracia de otras formas de dominio sustentadas en el trabajo de simples aficionados o personas cercanas a la autoridad. Esta capacidad también puede apreciarse en términos de utilidad, pues maximiza beneficios a menor costo; una organización colegial u honorífica es siempre más cara, pues su inespecificidad los lleva a delegar sus tareas en una aparato subalterno y oficinesco, lo que termina haciendo mucho más costosa la tarea (Weber, 2012: 731). Pero además de la eficiencia, la burocracia permite un mayor control y previsión de resultados sobre cualquier otra forma de dominación. Esta característica la designa Weber como calculabilidad (Berechenbarkeit), y se refiere la capacidad de ejercer control, o mejor aún, a la creencia de que todas las cosas

10 En este punto laten las famosas imágenes de Weber presentes en su escrito más célebre La Ética protestante y el espíritu del capitalismo. Si bien esta obra no se refiere explícitamente a la burocracia, cierra comentando cómo la racionalización de las estructuras vitales y la tecnificación de la profesión conducen a una pérdida de libertad individual caracterizada como «jaula de hierro» $y$ «petrificación mecanizada» (Weber, 2013: 259). 
pueden ser dominadas utilizando el cálculo. La calculabilidad o previsibilidad se produce gracias a que todas las tareas están racionalmente reglamentadas, o bien, proceden de acuerdo a reglas conocidas, lo que inmuniza a las organizaciones de decisiones discrecionales o irracionales (Weber, 2012: 732).

Conviene retener esta caracterización realizada por el pensador germano, pues MacIntyre lanzará su crítica a los dos atributos mencionados, es decir, a la eficacia y la calculabilidad, en la medida que ambas intentan imponerse como rasgos legitimadores de la autoridad burocrática. ${ }^{11}$

La crítica a la ideología de la autoridad burocrática antes de Tras la virtud

Como etapa previa a la revisión de la presencia ambivalente de Max Weber en Tras la virtud, es ilustrativo atender la crítica que MacIntyre dirige directamente a la «autoridad burocrática». Hasta donde sabemos, la primera vez que MacIntyre hace referencia a la ideología burocrática es en un artículo de 1977, que lleva el extenso título de "Utilitarianism and the Presuppositions of Cost-Benefit Analysis: An Essay on the Relevance of Moral Philosophy to the Theory of Bureaucracy". En este trabajo MacIntyre proporciona una definición importantísima para nuestra investigación: "La burocracia ha sido concebida, desde Weber, como un instrumento impersonal para la realización de fines dados" (MacIntyre, 1977: 217). Esta definición no solo es relevante porque permite comprender la burocracia como un fenómeno genérico, que resulta válido tanto para el gerente de una corporación privada como para la autoridad de una institución gubernamental, ella es relevante porque explica el núcleo de lo que será la crítica de MacIntyre a este tipo de dominación: su pretendida distancia o neutralidad con respecto a los fines. Para ilustrar este punto, el pensador escocés da cuenta del análisis costo beneficio que está presente en la

11 "Among the central moral fiction of age we have to place the peculiarly managerial fiction embodied in the claim to possess systematic effectiveness in controlling certain aspects of social reality" (Maclntyre 2007: 88). 
toma de decisiones del ejecutivo imbuido de una visión burocrática. El burócrata suele actuar como si las decisiones que tomara al mando de una organización cualquiera se limitaran a problemas económicos referidos simplemente a utilizar los escasos recursos para maximizar las utilidades. Sin embargo, MacIntyre muestra que hay buenos argumentos para pensar que este análisis esconde -como sucede con toda forma de utilitarismo- una serie de creencias, decisiones y compromisos previos que no son económicos, sino que son, justamente, morales. ${ }^{12}$ Así, si pensamos, por ejemplo, en la decisión de preferir un cierto tipo de neumáticos en una empresa automotriz o la cantidad de azúcar utilizada en un producto de la industria alimentaria, no costará percatarse que detrás de estas decisiones técnicas existe una profunda dependencia de cuestiones éticas o políticas. Repárese, en primer lugar, en la cantidad de alternativas a considerar en este tipo de decisiones. Esto no puede hacerse sólo con argumentos económicos referidos a los medios más idóneos. Si se decide comprar o no neumáticos a países con poca regulación laboral o considerar otras fuentes de endulzantes que pueden ser cancerígenos (los ejemplos son nuestros), no es un asunto que pueda resolverse sólo bajo el análisis de relación costo-beneficio. $\mathrm{Ni}$ es una cuestión meramente técnica, en segundo lugar, el periodo de tiempo en el que se enmarcan estas decisiones, pues no es éticamente irrelevante pensar para los próximos cinco años o para las generaciones futuras. Como tampoco lo es qué voces se escuchan y cuáles se desoyen: una empresa de automóviles probablemente escuche poco a los medioambientalistas y mucho a los accionistas, y una empresa de alimentos debe seguramente oír más a ciertos estratos sociales y rangos etarios que a otros. Lo interesante es que MacIntyre identifica, además, el recurso que le permite justamente al burócrata eclipsar o soslayar las cuestiones referidas a fines. Se trata de restringir el ámbito de decisiones a aquellos aspectos que son calculables y predecibles, ${ }^{13}$ dejando fuera todo

12 "The use of cost-benefit analyses clearly presupposes a prior decision as to what is a cost and what a benefit; but more than that it presupposes some method of ordering costs and benefits" (Maclntyre, 1977: 223).

13 "But problems of a cost-benefit kind - of a utilitarian kind in general- can only be 
lo demás. "Las consideraciones morales subyacentes a los análisis de costo beneficio - son las palabras con las que cierra este trabajo- resultan simplemente suprimidas" (MacIntyre, 1977: 232).

En un segundo artículo del año 1979, recogido en MacIntyre Reader, el filósofo escocés vuelve al tema de la burocracia, pero no desde la idea de utilidad; su punto de partida es la autoridad burocrática como paradigma de lo que él entiende por ideología. Nos referimos a "Social Science Methodology as the Ideology of Bureaucratic Authority". De acuerdo a MacIntyre, una ideología es una conceptualización de la vida con pretensiones de ser meramente descriptiva de la realidad, pero que más bien oculta las intenciones prácticas de un determinado grupo (MacIntyre, 1979: 59). Esta se presenta con tres características distintivas: la primera consiste en expresar una verdad de modo parcial, no es así una teoría falsa, sino más bien una visión fragmentaria con aspiración a ser omniabarcante de la realidad. El segundo rasgo de una ideología está dado por el ocultamiento de los motivos o fines de quienes la sostienen. Respaldada por criterios de objetividad aparentes o intenciones puramente epistemológicas, ella aparece como si sus defensores carecieran de intereses pragmáticos o utilitarios. El tercer rasgo de una ideología es su capacidad de ocultar el conflicto, la disputa y la imprevisibilidad de las prácticas. En esa línea, es una sobre simplificación reductiva de la realidad que recorta sólo los aspectos o variables disponibles para privilegiar el orden y la regularidad (MacIntyre, 1979: 59-60). Este último punto es especialmente relevante aplicado a la «ideología burocrática», pues ella se caracteriza justamente por marginalizar el conflicto y las disputas dentro de una organización.

La crítica a la autoridad burocrática en Tras la virtud

Tras la virtud, cuya primera edición data de 1981, dedica varios capítulos a la autoridad burocrática de raíz weberiana. Este tema es

solved when all elements of the problems are treated as belonging to the realm of the calculable and predictable" (Maclntyre, 1977: 222). 
tratado desde distintas perspectivas, las que van entretejiéndose con los argumentos críticos que MacIntyre dirige al discurso moral moderno. No es una tarea simple comprender este análisis en toda su profundidad, y un lector primerizo puede soslayar todas las dimensiones del mismo. La razón que dota de complejidad el contenido de estos capítulos del libro es triple. Por una parte, sucede que esta riquísima obra es, de acuerdo al testimonio de su autor, el resultado de la suma de dos propuestas distintas de investigación: la primera referida a los fundamentos de la argumentación ética contemporánea; la segunda, a las categorías académicas imperantes en las ciencias sociales contemporáneas (MacIntyre, 1983: 447). El problema es que la autoridad burocrática se encuentra en una especie de cruce o intersección de estas dos aproximaciones. La segunda razón que enreda el asunto, radica en que el mismo MacIntyre no es claro para explicar esta noción: por una parte, la autoridad burocrática parece referirse al poder que tiene el gerente al interior de las organizaciones burocráticas; pero en un mismo párrafo puede decir que la autoridad gerencial (managerial authority) es aquella que encuentra su justificación en las burocracias; y que, a su vez, los gerentes incorporan en su conducta la autoridad burocrática (bureaucratic authority) (MacIntyre, 2007: 31). En ese sentido, no resultaría relevante la distinción entre burócrata y gerente, y pueden usarse como términos intercambiables. Por último, el asunto se complica por una tercera razón: se trata del interés de MacIntyre por descubrir las convergencias entre la moral y la narración, tarea que lo lleva a utilizar términos sacados de la actuación teatral para explicar sus ideas. Así, el burócrata es un personaje (character), la autoridad burocrática un retrato (portrait), sus técnicas son simulacros histriónicos (histrionic mimicricy), y su prestigio se sustenta en una ficción (fiction).

Sin embargo, si se atiende más la crítica a la autoridad burocrática que al tratamiento conceptual del término, el asunto se simplifica gracias a la insistencia del mismo MacIntyre. Su propuesta está enfocada en desenmascarar al personaje del gerente o burócrata, en su carácter de ideal moral de la cultura moderna. No son los únicos paradigmas, también arremete contra el Rico esteta (Aesthete) y el Terapeuta (Therapist); pero mientras estos parecen mantenerse más vulnerables a las 
críticas hechas al interior de la sociedad, el manager, representaría -en palabras de MacIntyre- "la figura dominante de la escena contemporánea" (MacIntyre, 2007: 87-88). Dado que el esfuerzo de buena parte de Tras la virtud consiste en demostrar el fracaso del proyecto moderno, lo mismo que la debilidad del discurso moral contemporáneo, el personaje del gerente constituye el blanco predilecto de su ataque. ${ }^{14}$ De alguna manera, parecería pensar MacIntyre, si se desploma este personaje distintivo de una época, cae con él toda la obra.

Si se entiende este punto estamos en condiciones de atender a la crítica del pensador británico. Su estrategia se sustenta en deslegitimizar los fundamentos del gerente o experto en burocracia, apuntando a mostrar el carácter ficticio o espurio de sus atributos. Esto es tremendamente relevante por una razón que parece inadvertida para los críticos de MacIntyre. El reproche a la perspectiva weberiana sobre la burocracia no se apoya -como ha visto Tester o du Gay- en juzgar la filosofía de su contrincante desde sus propias categorías aristotélicas o tomistas. Esas categorías aparecen más bien en un segundo plano. Lo que hace MacIntyre es atacar al personaje del gerente desmantelando la ideología que lo avala, demostrando sus propias incoherencias, y enfatizando lo que ésta calla o supone como dato incuestionable.

En términos generales, MacIntyre irrumpe contra la autoridad gerencial burocrática por la misma razón que ha criticado a Max Weber: su «emotivismo». No es un emotivismo explícito, como el que fue sostenido por los filósofos de Cambridge de principios de siglo, ${ }^{15}$ sino más bien la asunción tácita de sus postulados. Este «emotivismo» estaría, además, en la raíz de la cultura moderna del siglo XX. Este

14 "A central way in which Macintyre has stung the contemporary world is through his identification of the bureaucratic manager as the antihero of our age. In Macintyre's writing, the manager emerges as a central character, perhaps the key villain in his account of the drama of contemporary social life, the protagonist in his criticism of modern, enlightenment rationality" (Beabout, 2013: 36).

15 Maclntyre proporciona él mismo una definición de emotivismo: "Emotivism is the doctrine that all evaluative judgments and more specifically all moral judgments are nothing but expressions of preference, expressions of attitude or feeling, insofar as they are moral or evaluative in character [...] C.L. Stevenson, the single most important exponent of the theory, asserted that the sentence 'This is good' means roughly the same as «l approve of this; do so as well»" (Maclntyre, 2007: 13-14). 
es una cuestión compleja, sobre la que no vale incursionar en este trabajo, pero MacIntyre descubre en los representantes de la Modernidad presupuestos emotivistas en el tratamiento de los asuntos prácticos; es decir, no tanto una teoría sobre el significado de los términos morales, como una mentalidad que impregna el modo de abordar los asuntos humanos: políticos, económicos, sociales y psicológicos. De modo más preciso, el emotivismo significa un relegamiento de las cuestiones sobre los fines últimos, consideradas como asuntos de preferencias o de valoraciones subjetivas, para detenerse sólo en la determinación y discusión racional sobre los medios a utilizar. "Las preguntas sobre los fines son preguntas sobre los valores, y en este punto la razón calla” (MacIntyre, 2007: 30, 43). Es difícil menospreciar los alcances de este silencio sobre los problemas éticos de fondo, pero al menos, en principio, podemos decir que esto implica una subordinación de lo moral frente a lo técnico, pues sólo este último aparece como objeto de atención racional o de una racionalidad compartida públicamente. Pero, además, desde la perspectiva contenida en Tras la virtud, una «mentalidad emotivista» conlleva -quizás sin proponérselo- a la despersonalización de las relaciones humanas, pues las personas aparecen como recursos materiales, no como fines en sí mismos para utilizar la terminología kantiana. A esto, MacIntyre lo denomina la distinción entre relaciones sociales manipuladoras y no manipuladoras, que sería borrada precisamente en el emotivismo (MacIntyre 2007: 27). Es importante retener esta crítica, pues va a ser trasladada precisamente a la autoridad gerencial o burocrática: el problema de esta forma de ejercicio es que su poder proviene precisamente de presentarse como un dominio técnico, fundado desde razones plausibles y fácilmente demostrables como óptimas, inmunes a la discusión sobre los fines intentados. Esto es algo semejante a lo que hace el terapeuta, pero mientras éste lo hace en el ámbito de la esfera privada, aquél lo lleva al terreno de las organizaciones y de la sociedad:

El gerente (manager) trata los fines como algo dado, como si estuviera fuera de su perspectiva; su comportamiento es técnico, tiene que ver con la eficacia en trasformar las materias primeras 
en productos acabados, el trabajo inexperto en trabajo experto, las inversiones en beneficios. El terapeuta también trata los fines como algo dado [...] Ni el gerente ni el terapeuta, en sus papeles de gerente y terapeuta, entran ni pueden entrar en el debate moral. Se ven a sí mismos, y son vistos por los que los miran con los mismos ojos, como figuras incontestables, que por sí mismas se restringen a los dominios donde el acuerdo racional es posible, naturalmente desde sus puntos de vista sobre el reino de los hechos, el reino de los medios, el reino de la eficacia mensurable (MacIntyre, 2007: 48-49).

Si se toma en serio esto que venimos diciendo, se está en condiciones de comprender el entramado crítico que MacIntyre dirige a la autoridad burocrática. Su primer reproche apunta a la pretensión de eficacia del gerente como un terreno neutral. Pero esto no impide, si no que más bien posibilita, comprender entonces que la crítica del pensador británico no apunta a la pericia gerencial en su capacidad performativa, el problema más bien es que esta aparezca como una habilidad meramente técnica o axiológicamente neutra. Para MacIntyre esto es más bien una presunción emotivista, y típicamente moderna, que se arraiga en la espuria distinción entre hecho y valor. Una suposición sobre la que MacIntyre lanza toda su artillería, pues armado con municiones que le ha proporcionado la filosofía de la ciencia, el pensador anglosajón considera que no existe la neutralidad despojada de interpretación o de valoración, y que esto no es más que un invento cultural del empirismo de los siglos XVII y XVIII (MacIntyre, 2007: 93-94). En otras palabras, MacIntyre no duda de la capacidad ejecutiva que pueda tener un gerente al interior de una organización, como tampoco duda de la habilidad del terapeuta en la vida de las personas, el problema es que esta aparezca con el manto de sacralidad que le proporciona la supuesta objetividad de la técnica:

Los propios gerentes y muchos de los que escriben sobre gerencia se conciben como personajes moralmente neutrales, cuya formación los capacita para trazar los medios más eficientes de 
obtener cualquier fin que se propongan. Si un gerente dado es eficaz o no, para la opinión dominante es una cuestión completamente diferente de la moralidad de los fines a que su eficacia sirve o fracasa de servir (MacIntyre, 2007: 88; 101 de la versión castellana).

Por lo demás, para el británico la idea de «eficacia» es, aunque intente o parezca lo contrario, un concepto moral. Un concepto que además se utiliza - y aquí aparece todo el dramatismo- para dirigir a los seres humanos y controlar las organizaciones (corporaciones privadas, agencias gubernamentales, sindicatos, colegios profesionales) de acuerdo a criterios utilitarios que subrepticiamente pasan como «racionales», cuando en realidad solo responden a preferencias particulares de los actores que dominan la escena. Es esta la razón por la que MacIntyre considera la noción de eficacia como una ficción moral, semejante a los conceptos de «utilidad»o «derechos humanos», donde es menos importante la realidad significada que su poder persuasivo.

El análisis anterior quedaría incompleto si no se atiende a la capacidad en la que aparentemente descansaría la eficacia del gerente: poseer un conjunto de conocimientos por medio de los cuáles puede modelar las organizaciones y las estructuras sociales. En efecto, realizado el cuestionamiento a la noción de efectividad, MacIntyre ataca, en segundo lugar, la autoridad epistemológica del burócrata weberiano. Para tal efecto, analiza la pretensión del gerente o manager de contar con un control predictivo y un conocimiento exhaustivo de la conducta humana, pretensión que se funda en una aplicación ilegítima del modelo de las ciencias experimentales en el ámbito de las organizaciones.

De acuerdo a MacIntyre, la ilusión de que existen leyes con las que es posible modelar el comportamiento humano, al modo cómo las leyes de la física o la química rigen la naturaleza, no es más que "profecía disfrazada de logro real" (MacIntyre 2007: 100). El capítulo 8 de Tras la virtud titulado "The Character of Generalization in Social Science" está dedicado a enjuiciar la figura del experto (también del científico social) que intenta aplicar un programa mecanicista a 
su disciplina, sin reparar en su «falibilidad» predictiva. No es factible en este trabajo detenerse en los ejemplos y argumentos con los que MacIntyre intenta refutar el poder predictivo de las ciencias humanas, basta decir que estas ciencias parecen no reconocer que siempre puede existir un contraejemplo impredecible, y que es imposible contemplar todos los factores involucrados en una situación concreta o los muchos accidentes imponderables. Ni siquiera una máquina o un computador pueden asegurarnos previsibilidad, desde que este mismo aparato puede estar sujeto, a su vez, a contingencias externas. Esto que es válido para la sociedad, no lo es menos para las mismas organizaciones y la pretendida capacidad vaticinadora de los ingenieros sociales. De hecho, llevado a este plano, la misma predictibilidad estaría reñida con la eficacia, pues las organizaciones son exitosas en la medida justamente que se adaptan a nuevas situaciones (MacIntyre 2007: 123).

No quiero decir que las actividades de los supuestos expertos no tengan efectos, que no padezcamos tales efectos y que no los padezcamos gravemente. Sin embargo, la noción de control social encarnada en la noción de pericia es, en realidad, una ficción. Nuestro orden social está, en el sentido más literal, fuera de nuestro control y del de cualquiera. Nadie está ni puede estar encargado de él. Por lo tanto, la creencia en la pericia gerencial es, tal como yo la veo, muy parecida a la creencia en Dios tal como la pensaron Carnap y Ayer. Es una ilusión más, típicamente moderna, la ilusión de un poder externo a nosotros mismos y que se ejerce en nombre del interés bien entendido (MacIntyre 2007: 124; 138-139 de la versión castellana).

Dado que la noción de experticia es solo una ficción instalada con fines retóricos, fundada en su capacidad afectiva de persuadir y manipular para conservar el poder, MacIntyre considera que el proyecto de Max Weber pierde todo sustento racional; y, por ende, la autoridad del gerente o burócrata queda sin fundamento alguno de legitimidad; y, lo señala, oculta más que ilumina, y hace depender su poder justamente de este ocultamiento (MacIntyre 2007: 127). 
El resurgimiento de MaxWeber en la configuración de la ética de las virtudes

A partir de lo expuesto en los apartados anteriores, resultaría errado suponer que, con la crítica a la ideología burocrática, MacIntyre da por superado a Max Weber. Es cierto que desde el capítulo 9 de Tras la virtud el objetivo es presentar la «tradición clásica» de las virtudes como un intento de marcar un nuevo punto de partida en el que pueda fundarse el discurso moral contemporáneo. Sin embargo, si se comprende a fondo lo que el filósofo escocés hace en esta obra, es posible darse cuenta que en su versión de la ética aristotélica de las virtudes también encierra una contestación a la propuesta weberiana capaz de hacer frente a los ideales de eficiencia, previsibilidad y control. Es más, creemos que mucho más presente que las mismas categorías clásicas, está Weber en el corazón de la caracterización que hace MacIntyre de la virtud, aunque ni siquiera él mismo sea completamente consciente de esta deuda.

Apenas presentada las distintas concepciones de la virtud, la homérica, la aristotélica-cristiana, y la de Benjamín Franklin y Jane Austen; ${ }^{16}$ MacIntyre se pregunta si es posible pensar, en medio de estas versiones, en una idea unitaria y central de virtud. Su respuesta es afirmativa, pero condicionada a que la virtud deba ser siempre comprendida a partir de tres nociones superiores: como «práctica» (practice), conforme a un orden narrativo propio de la vida humana (narrative order of a single human life) y embebida en una «tradición de investigación moral» (tradition of moral enquiry) (MacIntyre, 2007: 217-218). ¿Cuál es la importancia de estos conceptos? Si seguimos al mismo MacIntyre, estas nociones le van a permitir adoptar la ética de las virtudes aristotélica sin necesidad de recurrir a la "biológica metafísica" del Estagirita, contra la que ha tratado de zafarse en buena parte de Tras la virtud (MacIntyre, 2007: 229).

16 No deja de ser interesante que la caracterización más sobresaliente de Benjamín Franklin, como modelo de una nueva visión de virtudes, en las que destaca la "honradez, la puntualidad, la laboriosidad y la moderación" en razón de su «utilidad profesional», no es original de Maclntyre, sino que está antes presente en La ética protestante y el espíritu del capitalismo de Weber (Weber, 2013: 108 y ss.). 
Sin embargo, aun cuando pudiera resultar cierta esta aseveración, resulta insuficiente debido a que no alcanza a explicar positivamente cuál es el contexto de descubrimiento en que surgen estas ideas. Nuestra tesis es que estas tres nociones claves reaparecen como contrapunto al mismo discurso weberiano, y solo frente a éste, aparece la verdadera armonía. Los argumentos que se presentan a continuación ordenan cada una de las ideas que se relacionan con la ideología burocrática o gerencial, en vista de descubrir si se sostiene o no la propuesta de esta investigación.

En primer lugar, la virtud se entiende en relación con una «práctica». Con este último término MacIntyre engloba una serie de actividades realizadas de modo sistemático y de manera colaborativa: actividades lúdicas, investigaciones científicas o la conformación de una comunidad. Estas prácticas se constituyen desde dos tipos de bienes: los bienes internos propios de la misma actividad, y los bienes externos o bienes contingentes. Los primeros aparecen sólo para quienes se comprometen con la actividad en cuestión, mientras que los segundos pueden obtenerse desde otras actividades. El ejemplo del juego de ajedrez como práctica que proporciona el mismo MacIntyre se ha vuelto clásico: el niño que juega ajedrez por los premios no ha alcanzado aún los bienes propios de esta actividad (agudeza analítica, imaginación estratégica e intensidad competitiva); están reservados a quienes se han comprometidos con los valores intrínsecos del juego. Es cierto que el niño puede ser tan exitoso trabajando por los dulces que haciéndolo por el mero gusto de jugar; sin embargo, sólo alcanzará la excelencia de la actividad identificándose y participando en los bienes inherentes al juego que practica, sin hacer de éste un simple instrumento para obtener algún tipo de recompensa.

¿Cuál es la relación de una práctica con la virtud? La virtud es esa cualidad sobresaliente cuya posesión y ejercicio nos permite alcanzar los bienes propios de las prácticas. ${ }^{17}$ Así, la virtud del que

17 " $\mathrm{A}$ virtue is an acquired human quality the possession and exercise of which tends to enable us to achieve those goods which are internal to practices and the lack of which effectively prevents us from achieving any such goods" (Maclntyre, 2007: 222). 
interpreta un instrumento musical o investiga la cura de una rara enfermedad, es justamente esa cualidad que le permite a un sujeto la excelencia de la interpretación o la investigación de manera excelente. En verdad que un músico y un científico pueden estar movidos por la fama o la fortuna, pero estas son bienes externos a las prácticas que podrían obtenerse de otra manera. Bienes como el prestigio (prestige), el rango (status) y el dinero (money); son conseguidos de forma oblicua, es decir, no como parte de la práctica, sino más bien como resultado de la deformación de ésta. No cabe duda que presentado así, el concepto de «práctica» está asociada con una distinción de cuño aristotélico entre bienes que se eligen por sí mismos y bienes utilitarios, lo mismo que con la noción de praxis como acción inmanente; sin embargo, esto no es todo. Es especialmente relevante comprender la naturaleza de las prácticas en oposición con dos conceptos claves: las prácticas se distinguen de las meras habilidades técnicas y las prácticas se contraponen a las instituciones. Un texto del mismo MacIntyre ilustra bien este punto:

Por supuesto, las prácticas no sólo deben ser contrastadas con un conjunto de habilidades técnicas. Las prácticas no deben confundirse con las instituciones. El ajedrez, la física y la medicina son prácticas; los clubes de ajedrez, los laboratorios, las universidades y los hospitales son instituciones. Las instituciones están característica y necesariamente comprometidas con lo que he llamado bienes externos. Ellas están envueltas en conseguir dinero y otros bienes materiales; se estructuran en términos de poder y estatus, y distribuyen dinero, poder y estatus como recompensas. No podrían actuar de otro modo, puesto que deben sostenerse a sí mismas y sostener también las prácticas de las que son soportes. Ninguna práctica puede sobrevivir largo tiempo si no es sostenida por instituciones. De hecho, es tan íntima es la relación entre prácticas e instituciones -y en consecuencia de los bienes externos con los bienes internos a la práctica en cuestión- que instituciones y prácticas forman típicamente un orden causal único, en donde los ideales y la creatividad de la práctica son siempre vulnerables a la codicia de la institución, donde la 
atención cooperativa al bien común de la práctica es siempre vulnerable a la competitividad de la institución. En este contexto, la función esencial de las virtudes está clara. Sin ellas, sin la justicia, el valor y la veracidad, las prácticas no podrían resistir al poder corruptor de las instituciones (MacIntyre, 2007: 226; 241 de la versión castellana).

Es decir, las prácticas no aparecen solo en relación con Aristóteles, sino que aparecen como «formas de resistencia» a las estructuras administrativas de dominio. ${ }^{18}$ Es cierto que una práctica requiere también establecerse al interior de una institución, pero de alguna manera lo que tenemos en las prácticas son espacios en lo que puede primar la creatividad y el valor, mientras las instituciones representan estructuras de competencia y control. Esto que venimos exponiendo será refrendado por una distinción que MacIntyre realiza en Whose Justice? Which Rationality. Mientras las prácticas se relacionan con los bienes de la excelencia, las instituciones se vinculan con bienes de eficacia (MacIntyre, 2001: 45). Es decir, si queremos descubrir un primer contrincante de la idea weberiana de la eficiencia de las organizaciones burocráticas, la hemos encontrado: se trata de la excelencia de las prácticas. Las prácticas aparecen como espacios protegidos frente a la «colonización» mecanicista de los sistemas burocráticos, por usar una expresión habermasiana. ${ }^{19}$ En efecto, solo las prácticas se constituyen como espacios no contaminados por la efectividad de una racionalidad instrumental, marcada por el dinero

18 Las prácticas en Aristóteles -como señala Kelvin Knight- se contrastan con la producción y la teoría, no con las instituciones. De ahí que este mismo autor reconozca en este concepto una influencia de la idea de juego de Wittgenstein y mucho de Max Weber (Knight 2007: 147-159).

19 Resultaría interesante realizar una comparación entre instituciones y «prácticas» de Alasdair Maclntyre, y las nociones de «sistema» $y$ «mundo de la vida» de Jürgen Habermas. Aventuramos que la oposición en el alemán es más marcada, pues para el británico las prácticas solo son posibles sostenidas en instituciones; sin embargo, no debe olvidarse que estas coincidencias tienen sentido, desde que ambos pensadores comparten un enfoque semejante (un discurso moral en relación con la sociología) y han sido alimentados con los mismos maestros: Marx, Weber, Lukács, Marcuse. En todo caso, aquí sólo dejamos anunciada esta problemática para una próxima investigación. 
y el poder; pues ellas se configuran, muy por el contrario, como instancias colaborativas destinadas a desarrollar sus fines propios. De este modo, se podría decir que las prácticas posibilitan, en definitiva, superar la racionalidad instrumental de los medios para dar paso a una racionalidad de fines no subjetiva o no manipuladora.

A esta primera consideración, se agrega una segunda, que apunta a comprender las virtudes no sólo en términos de prácticas, sino que en relación con aquellas cualidades que permiten sostener la unidad de la vida humana (MacIntyre, 2007: 254). En vista de superar la Modernidad fragmentada que parcializa la vida en ámbitos (ocio-trabajo, individual-corporativo), así como las filosofías que tienden a pensar atomísticamente la acción humana separada de un contexto interpretativo; MacIntyre recurre a la idea de historia narrativa (narrative history) para caracterizar la vida de los sujetos. De esta manera, la narración se convierte en la forma privilegiada para entender nuestras acciones y la de los demás ${ }^{20}$. Sobre la base de lo expuesto, dos características aparecen como propias de toda narración vivida: su carácter teleológico y la no predictibilidad de los acontecimientos. ${ }^{21}$ La vida tiene un fin o meta que da sentido a las acciones propias del ser humano, haciéndolas inteligibles; pero, a su vez, esta misma vida está plena de elementos que no pueden ser previstos, con limitaciones y posibilidades cerradas. Ahora bien, si se considera con atención estos aspectos, vuelve a aparecer Max Weber como el interlocutor antagónico de las tesis macinteryanas. En primer lugar, porque la narratividad aparece para hacer frente a una idea cara de Max Weber: la Modernidad nos ha llevado a vivir en distintas esferas en las que cada una (económica, políticas, artísticas)

20 Como ha observado Gregory Jones, Maclntyre no usa de forma unívoca esta idea de narración. De hecho, este estudioso ha identificado siete diferentes modos de comprender el término de narrativo en Tras la virtud. Sin embargo, al menos es claro que "Maclntyre believes that human action, in order to be intelligible, require an account of a context which only a true dramatic narrative can provide" (Gregory Jones 1987: 57).

21 "Unpredictability and teleology therefore coexist as part of our lives; like characters in a fictional narrative we do not know what will happen next, but nonetheless our live have certain form which projects itself toward future. Thus the narratives which we live out have both an unpredictable and a partially teleological character" (Maclntyre 2007: 250). 
posee sus propios valores, los que chocan unos con otros ${ }^{22}$. Pero, además, en segundo lugar, la oposición resulta manifiesta si comprendemos que mientras el burócrata actúa en término de cuentas perfectamente calculables, MacIntyre ha decidido destacar mediante el concepto de narratividad el carácter no disponible de la vida (más cuento que cuentas), con una riqueza de posibilidades y unicidad que no se deja atrapar por formas alienantes de control ni abordar en su totalidad por conocimientos genéricos.

El último de los conceptos que aparece ligado a la virtud es el de «tradición». Las virtudes se desarrollan dentro de contextos históricos particulares o embebidas en determinadas "tradiciones" (MacIntyre 2007: 258). Pero MacIntyre no entiende la tradición simplemente como la herencia de un pasado que permanece como lo estable en el cambio. Para MacIntyre éste es el modo burkeano o conservador de comprender la tradición. La tradición es más bien el espacio desde el cual una comunidad de participantes desarrolla una discusión a través del tiempo. Ejemplo de tradiciones son la tradición aristotélica y la galileana en el ámbito de la investigación física; la liberal y la marxista en el ámbito de la política; o la tradición judía y cristiana en la religión. ${ }^{23}$ Lo característico de una tradición -si está en etapa de crecimiento o consolidación- es que ésta entre en conflicto con su oponente rivalizando por quién tiene una mejor explicación o una respuesta más rica. "Las tradiciones, cuando están vivas, incorporan continuamente el conflicto” (MacIntyre, 2007: 257). ${ }^{24}$

22 Es cierto que Maclntyre también piensa que la vida de los sujetos depende del rol que le corresponde vivir, contexto que es determinante para las virtudes a desarrollar (como hijo, con determinada profesión, como ciudadano de determinada comunidad); sin embargo, este particularismo es siempre unificado en la noción de la vida como totalidad (Maclntyre 2007: 236).

23 Con intención hemos señalado una tradición frente a otra opuesta. Pues hay algo fundamental en las tradiciones: estas no son sólo cuerpos doctrinales o dichos autorizados, son más bien ideas y creencias que va siendo alimentadas y retroalimentadas en vista -precisamente- de competir con otra tradición rival.

24 "For what constitutes a tradition is a conflict of interpretations of that tradition, a conflict which itself his a history susceptible of rival interpretations. If I am Jew, I have to recognize that the tradition of Judaism is partly constituted by a continuous argument over what it means to be a Jew. Suppose I am an American: the tradition is one partly 
En caso contrario, lo que tenemos es un apaciguamiento intencionado o una tradición decadente en vías de extinguirse o desaparecer. Esto es precisamente lo que hace a la tradición lo opuesto a la ideología burocrática, pues esta última se había caracterizado - tal como se había señalado con anterioridad- justamente por su capacidad de ocultar el conflicto y eliminar las discusiones. Mientras el símil de la tradición es el organismo vivo, el de la burocracia es la máquina bien aceitada para evitar fricciones.

Sin embargo, llegado a este punto, conviene también recordar a Weber. La oposición original entre burocracia y tradición no es de MacIntyre, sino que proviene de los análisis del sociólogo alemán, pues él había contrapuesto la forma de dominio burocrática, impersonal, técnica, a la dominación tradicional, lo mismo que a la autoridad carismática. Es cierto que Max Weber no está pensando en la tradición como ha hecho MacIntyre. Weber tiene en mente otra realidad muy distinta, sus investigaciones refieren a la autoridad representada por el "patriarcalismo" y "feudalismo" como contrapartida de la organización de "relaciones objetivas, de negocio" (Weber, 2012: 843). ${ }^{25}$ Sin embargo, es posible reconocer que este rechazo de MacIntyre a la autoridad burocrática desde la idea de «tradición», encierra una paradoja: el rechazo a la posición de Weber termina retornando hacia él. Paradoja que, en todo caso, reconoce el filósofo escocés, pues en su artículo "Social Science Methodology as the Ideology of Bureaucratic Authority", había admitido que es Max Weber el primero en introducir el concepto de burocracia para

constituted by continuous argument over what it means to be an American and partly by continuous argument over what it means to have tradition. If I am an historian, I must acknowledge that the tradition of historiography is partly, but centrally, constituted by argument about what history is and ought to be, from Hume and Gibbon to Namier and Edward Thompson. Notice that all three kinds of tradition -religious, political, intellectual, involve epistemological debate as a necessary feature of their conflicts (Maclntyre 1977b: 460-461).

25 Como dato a considerar, es interesante que Arthur Mitzman, en su famosa biografía sobre Weber, encuentra en el sociólogo alemán varias respuestas que se suceden a lo largo de los años como modo de hacer frente a la "petrificación mecanizada" de la burocratización: ascetismo, autoridad carismática, democracia parlamentaria. Entre ellas se destaca la tradición de los ideales aristocráticos premodernos y precapitalistas de base nietzscheana. Abordar esta temática sería motivo de una nueva investigación (Mitzman, 2005: 231 y ss.). 
contrastarlo con la tradición (MacIntyre 1998, 59-60). Y es que a MacIntyre parece pasarle - en definitiva- lo que él mismo había advertido para otros: "muchos sociólogos que creen haber repudiado el análisis de Weber lo reproducen en realidad” (MacIntyre 2007: $31,44)$.

\section{Referencias bibliográficas}

Albrow, M. (1979). Bureaucracy. London: MacMillan Press.

Balstad Brewer, K. (1997). "Management as a Practice: A Response to Alasdair MacIntyre”. En Journal of Business Ethics 16: 825-833.

Beabout, G. (2013). The Character of the Manager: From Office Executive to Wise Steward. Palgram: Macmillan.

Beadle, R.; R. Moore. (2006). "MacIntyre on Virtue and Organization”. En Organization Studies 23(3): 323-340.

Beetham, D. (1979). MaxWeber y la teoría política moderna. Madrid: Centro de Estudios Constitucionales.

Bendix, R. (2012). Max Weber (Max Weber: An Intellectual Portrait). Buenos Aires: Amorrortu Editores.

Blackledge, P; N. Davidson, eds. (2005). Alasdair MacIntyre's Engament with Marxism. Chicago: Haymarket Books.

Blackledge, P; K. Knight, eds. (2011). Virtue and Politics:Alasdair MacIntyre's revolutionary Aristotelianism. Notre Dame: University of Notre Dame Press.

Breen, K. (2012). Under Weber's Shadow: Modernity, Subjetivity and Politics in Habermas, Arendt and MacIntyre. Surrey: Ashgate Publishing.

Colino, C; E. del Pino, (2000). "Las dos caras de la administración burocrática en la obra de Max Weber”. En Revista de Ciencias Sociales, 19: 49-93.

Du Gay, P. (2000). En elogio de la burocracia:Weber, organización, ética, Madrid: Siglo XXI.

Ferrero I.; A. Sison (2014). "A Quantitative Analysis of Authors, Schools and Themes in Virtue Ethics Articles in Business Ethics and Management journals. Business Ethics: A European Review 23(4): 375-400.

Gregory Jones, L. (1987). "Alasdair MacIntyre on Narrative, Community, and the Moral Life”. En Modern Theology 4(1), 1987: 53-69.

Knight, K. (2007). Aristotelian Philosophy: Ethics and Politics from Aristotle to MacIntyre. 
Cambridge: Polity Press.

Knight, K. (2011). "Revolutionary Aristotelianism". En Virtue and Politcs: Alasdair MacIntyre's Revolutionary Aristotelianism. Paul Blackledge y Kelvin Knight, eds. Notre Dame: University of Notre Dame Press.

Knight, K. (2013). “Alasdair MacIntyre's Revisionary Aristotelianism: Pragmatism Opposed, Marxism Outmoded, Thomism Trasnformed”. En O’Rourke, F., ed. What Happened in and to Moral Philosophy in the Twentieth Century. Notre Dame: University of Notre Dame Press.

MacIntyre, A. (1977). "Utilitarianism and the Presuppositions of Cost-Benefit Analysis: An Essay on the Relevance of Moral Philosophy to the Theory of Bureaucracy”. En Wachs M., ed. Ethics in Planning. New Jersey: The Center for Urban Policy Research. pp. 216-232.

MacIntyre, A. (1977b), "Epistemological Crises, Dramatic Narrative and the Philosophy of Science”, The Monist 60(4): 453-472.

MacIntyre, A. (1979). "Social Science Methodology as the Ideology of Bureaucratic Authority”. En The MacIntyre Reader. Cambridge: Polity Press, pp.53-68.

MacIntyre, A. (1983). "Moral rationality, tradition, and Aristotle: A reply to Onora O'Neill, Raimond Gaita, and Stephen R. L. Clark”. Inquiry: An Interdisciplinary Journal of Philosophy 26 (4): 447-466.

MacIntyre, A. (2007). After Virtue. Londres. Nueva York: Bloomsbury.

MacIntyre, A. (1987). Tras la Virtud, A. Valcárcel, trad. Barcelona: Editorial Crítica.

MacIntyre, A. (2001). Whose Justice? Which Rationality. London: Duckworth.

Mitzman, A. (2005). The iron Cage: An Historic Interpretation of Max Weber. New Brunswick: Transaction Books.

Mommsen, W. (2007). The Political and Social Theory of MaxWeber. Cambridge: Polity Press.

Tester, H. (1999). “Weber's Alleged Emotivism”. En British Journal of Sociology 50(4): 563-573.

Weber, M. (2013). La ética protestante y el espíritu del capitalismo, J. Navarro Pérez, ed.; J.L.Villacañas, prólogo. Madrid: Ediciones Akal.

Weber, M. (2012). Economía y Sociedad: Esbozo de sociología comprensiva (Wirtschaft und Gesellschaft. Grundriss der Verstehenden Soziologie), J. Winckelmann, ed. México: Fondo de Cultura Económica.

Weber, M. (2008). Escritos políticos, J. Abellán, ed. Madrid: Alianza Editorial. 